\title{
Comparison of the
} functional responses of invasive and

\section{native amphipods}

\author{
Loic Bollache $^{1,2}$, Jaimie T. A. Dick ${ }^{2, *}$, \\ Keith D. Farnsworth ${ }^{2}$ and W. Ian Montgomery ${ }^{2}$ \\ ${ }^{1}$ Equipe Ecologie Evolutive, UMR CNRS 5561 Biogéosciences, \\ Université de Bourgogne, 6 Boulevard Gabriel, 21000 Dijon, France \\ ${ }^{2}$ School of Biological Sciences, Queen's University Belfast, $M B C, 97$ \\ Lisburn Road, Belfast BT9 7BL, Northern Ireland, UK \\ *Author for correspondence (j.dick@qub.ac.uk).
}

While we can usually understand the impacts of invasive species on recipient communities, invasion biology lacks methodologies that are potentially more predictive. Such tools should ideally be straightforward and widely applicable. Here, we explore an approach that compares the functional responses (FRs) of invader and native amphipod crustaceans. Dikerogammarus villosus is a PontoCaspian amphipod currently invading Europe and poised to invade North America. Compared with other amphipods that it actively replaces in freshwaters, $D$. villosus exhibited significantly greater predation, consuming significantly more prey with a higher type II FR. This corroborates the known dramatic field impacts of $D$. villosus on invaded communities. In another species, FRs were nearly identical in invasive and native ranges. We thus propose that if FRs of other taxa and trophic groups follow such general patterns, this methodology has potential in predicting future invasive species impacts.

Keywords: amphipod; functional response; invasive species; predation; prediction

\section{INTRODUCTION}

Our increased understanding of the patterns and processes associated with invasive species (sensu Ricciardi \& Cohen 2007) is now driving research into the prediction of identities and impacts of future invaders, but with limited success. Invasion history (Ricciardi 2003) and propagule pressure (Lockwood et al. 2005; von Holle \& Simberloff 2005) are useful predictors, but generally for known invaders and existing impacts (Ricciardi 2003). We can certainly list potential invaders and attempt preventative measures (Ricciardi \& Rasmussen 1998; Leppäkoski et al. 2002). However, prediction of community impacts of future invaders is much less certain, given that new potential invaders have little impact history. Further, with invasion 'donor hot spots' such as the Ponto-Caspian region that are likely to donate new invaders (see Leppäkoski et al. 2002), we need methods that not only enhance our understanding of invasive species impacts but also have the potential to be more predictive.

The 'functional response' (FR) quantifies trophic relations and, in particular, gives insights into predator behaviour and effects on prey populations (Holling 1959). However, FRs rarely feature in an invasion context (but see Hooff \& Bollens 2004; Radford et al. 2007), which is surprising, given the known impacts of introduced predators (Zaret \& Paine 1973; Dick et al. 2002; Wanless et al. 2007). Here, we compare the FRs of invader and native amphipods, elucidating the ecologically damaging impacts of the former. Further, we discuss the potential of comparative FRs as a predictive tool in invasion biology.

Amphipod introductions are global, being deliberate for fish feeding (Kelly \& Dick 2005) and accidental via ballast water and new canals (Tittizer 1996). Community impacts range from benign to drastic (Dick et al. 2002; Kelly et al. 2006; van Riel et al. 2006), with new invasions likely throughout Europe and North America (Ricciardi \& Rasmussen 1998; Dick et al. 2002). Although many amphipods are now viewed as predatory (Dick et al. 2002), their FRs remain unquantified. Here, we compare FRs to animal prey of: (i) Dikerogammarus villosus, a PontoCaspian invader in Europe, with known severe impacts on freshwater communities (van Riel et al. 2006), (ii) the native European Gammarus duebeni celticus, (iii) Gammarus roeseli, naturalised in France, and (iv) Gammarus pulex, as 'native' in Europe and 'invader' in Ireland.

\section{MATERIAL AND METHODS}

In January-April 2002 and 2003, we collected: D. villosus from the River Saône, France (Grid ref. 3124E); G. d. celticus from the R. Lagan, N. Ireland (J308646); G. roeseli from the R. Ouche, France (3122O); and G. pulex as 'invaders' from the R. Lagan (D335685) and as 'natives' from the R. Ouche. Juvenile Asellus aquaticus, an isopod prey of amphipods, were collected from a pond in N. Ireland (J334716) and the Tille River, France (3122O). At both Queen's University Belfast and CNRS, animals were kept in aquaria with water, substrate, leaf and animal material from source at $14^{\circ} \mathrm{C}$ and $10 \mathrm{~L}: 14 \mathrm{D}$ for 4 days before experiments and subsequently killed in warm water.

We selected similar-sized amphipods for experiments, following which we examined mean body length with respect to 'species/source population' (one-factor ANOVA). We presented single males (starved for 24 hours) with $A$. aquaticus (body length $3.9 \pm$ s.e. $0.5 \mathrm{~mm}$ ) at eight prey densities $(4,6,8,10,16,20,30,40 ; n=4$ per density) in glass dishes $(7.5 \mathrm{~cm}$ diameter) with $250 \mathrm{ml}$ of continuously aerated amphipod source water. Controls were four replicates of each prey density without amphipods. Replicates were initiated at 17.00 hours and examined at 16, 24 and 40 hours.

Mean prey eaten was examined with respect to 'species/population', 'prey density' and 'time' (latter as a repeated measure; three-factor ANOVA and Fisher's protected least significant difference (FPLSD) post hoc tests). FRs were modelled (SigmaPlot v. 8) using a Monod function $(y=a x /(1+b x))$, providing estimates of $a$ (the scale parameter) and $b$ (saturation parameter), maximum feeding rate (the asymptote $a /(b h)$, where $h$ is experimental time) and adjusted $R^{2}$ values for the fitted curves. Mean maximum feeding rate estimates were examined with respect to species/population (one-factor ANOVA).

\section{RESULTS}

Control $A$. aquaticus had high survival, $99.6 \%$ alive at 16 hours, $99.1 \%$ at 24 hours and $98.7 \%$ at 40 hours. Thus, experiment deaths were due to amphipod predation, which we also directly observed and was further evidenced by body parts on aquaria floors. There was no significant difference in body length of the five amphipod species/population groups $\left(F_{4,155}=2.3\right.$, n.s.; means $\left.15.3-15.7 \mathrm{~mm}\right)$. Mean number of prey eaten differed significantly among the five groups $\left(F_{4,240}=43.3, p<0.001\right.$; figure 1$)$, with significantly more prey eaten by $D$. villosus than all others 

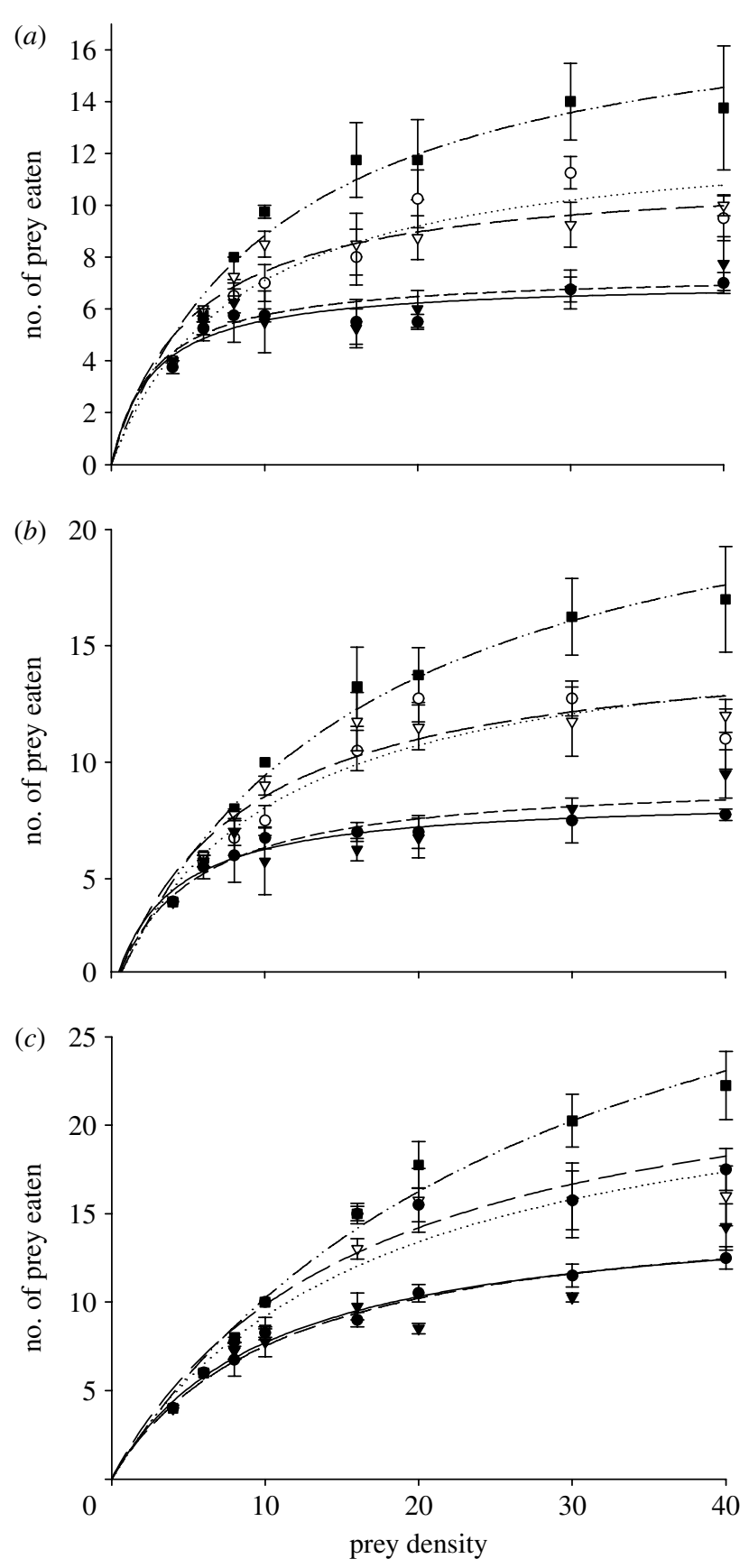

Figure 1. Relationship between number of prey eaten and prey density, the FR, for five amphipod species/populations at: (a) 16 hours, (b) 24 hours and (c) 40 hours. (Filled squares, D. villosus; open circles, $G$. d. celticus; open downtriangles, G. roeseli; filled downtriangles, G. pulex; Dijon; filled circles, $G$. pulex Belfast.)

(all $p<0.0001$; figure 1). Gammarus duebeni celticus and $G$. roeseli did not differ significantly in numbers of prey eaten nor did $G$. pulex from its two populations (FPLSD n.s.); however, the former two species killed more prey than the latter (all $p<0.001$ ). There were significantly more prey eaten at higher prey densities $\left(F_{7,240}=73.5, p<0.0001\right)$ and over time $\left(F_{2,240}=\right.$ 530.3, $p<0.0001)$. All two- and three-way interactions were significant.

Monod models of FRs achieved high goodness of fit (table 1), thus being statistically indistinguishable from type II FRs (but see Fussmann \& Blasius 2005). Maximum feeding rates (table 1) were significantly different among species/population groups
$\left(F_{4,10}=49.4, p<0.001\right)$, with $D$. villosus showing the greatest (all $p<0.001$ ) and $G$. d. celticus $/ G$. roeseli significantly greater than G. pulex Dijon/G. pulex Belfast (all $p<0.001$ ), but no significant differences within these pairings.

\section{DISCUSSION}

Dikerogammarus villosus has spread rapidly throughout Europe (van Riel et al. 2006). Early studies (Dick et al. 2002) indicated that its predatory behaviour may affect native fauna, and this is now confirmed (van Riel et al. 2006). Here, we compared the predatory impact of D. villosus with other amphipods that it replaces (primarily through intraguild predation; see Dick et al. 2002), namely $G$. duebeni, $G$. roeseli and $G$. pulex. Dikerogammarus villosus consumed more prey than the other species and its FR rises more rapidly and to a higher asymptote. We controlled for body size, but D. villosus reaches double the size of the other species (Dick et al. 2002) and predatory impacts here are probably conservative. Thus, we can now understand the impact of $D$. villosus and predict this will continue in recipient communities in Europe and perhaps North America, where Ponto-Caspian species continue to arrive (Ricciardi 2006). In addition, new amphipod invaders are moving west from the Ponto-Caspian, such as Obesogammarus obesus (Nehring 2006), and these could be assessed for their potential impacts via FR comparisons.

Furthermore, since species other than predators (of animal prey) can have their FRs measured, including parasitoids (e.g. Jones et al. 2003), herbivores and grazers (Beckerman 2005) and indeed plants (e.g. Radford et al. 2007), invasives and natives of these groups could have their FRs measured and compared. If the generality was established of higher FRs in damaging invaders when compared with more benign invaders and natives, then the methodology would have merit in the prediction of invaders. For example, the Ponto-Caspian is currently donating invasive fishes, amphipods, mysids and cladocerans throughout Europe and North America (see Leppäkoski et al. 2002; Ricciardi 2006). The FRs, once more widely derived, may potentially allow 'screening' as to which species might damage recipient communities.

Paradoxically, individuals of the Irish native, $G . d$. celticus, had a higher FR than the invader in Ireland, G. pulex, which replaces the native through intraguild predation (see Kelly et al. 2006). Compared with the native, G. pulex reduces species diversity and alters community structure, much of this through predation (Kelly et al. 2006) and hence we expected a greater FR of the invader. However, recovery of invaded communities is associated with reductions in abundance of this invader (Kelly et al. 2006). Thus, FRs may need to be assessed alongside invader abundances reached in communities. Dikerogammarus villosus has a much greater reproductive output than other native and invasive amphipods (Pöckl 2007) and becomes superabundant in invaded communities (van Riel et al. 2006). Thus, the most damaging future invaders will probably have greater inherent predatory abilities (FRs) than native individuals, be larger (see above) and 
Table 1. FR parameters ( $a$ and $b$ ) with goodness of fit (adjusted $R^{2}$ ) for each species/time combination (figure 1 ) and predicted maximum intake rate, $a /(b h)$, with standard errors (s.e.).

\begin{tabular}{|c|c|c|c|c|c|c|}
\hline species & time & $a$ & $b$ & $R^{2}$ adj & $a /(b h)$ & s.e. \\
\hline \multirow[t]{3}{*}{ D. villosus } & 16 & 1.683 & 0.097 & 0.951 & 1.16 & 0.38 \\
\hline & 24 & 1.520 & 0.061 & 0.964 & 1.03 & 0.29 \\
\hline & 40 & 1.375 & 0.346 & 0.982 & 0.99 & 0.21 \\
\hline \multirow[t]{3}{*}{ G. duebeni } & 16 & 1.562 & 0.120 & 0.964 & 0.81 & 0.23 \\
\hline & 24 & 1.604 & 0.995 & 0.963 & 0.67 & 0.19 \\
\hline & 40 & 1.470 & 0.060 & 0.963 & 0.62 & 0.17 \\
\hline \multirow[t]{3}{*}{ G. roeseli } & 16 & 2.191 & 0.194 & 0.971 & 0.70 & 0.21 \\
\hline & 24 & 1.902 & 0.123 & 0.970 & 0.65 & 0.17 \\
\hline & 40 & 1.603 & 0.063 & 0.973 & 0.64 & 0.21 \\
\hline \multirow[t]{3}{*}{ G. pulex (D) } & 16 & 2.608 & 0.353 & 0.940 & 0.46 & 0.26 \\
\hline & 24 & 1.952 & 0.208 & 0.952 & 0.39 & 0.16 \\
\hline & 40 & 1.425 & 0.089 & 0.970 & 0.40 & 0.10 \\
\hline \multirow[t]{3}{*}{ G. pulex (B) } & 16 & 2.566 & 0.362 & 0.958 & 0.44 & 0.21 \\
\hline & 24 & 2.388 & 0.281 & 0.966 & 0.35 & 0.13 \\
\hline & 40 & 1.528 & 0.098 & 0.987 & 0.39 & 0.06 \\
\hline
\end{tabular}

exhibit higher fecundity. Indeed, it is unlikely that any one biological or ecological trait can predict invasive species, be they gammarids or other taxa (see Devin \& Beisel 2007). However, FRs in conjunction with a few other traits may be powerful predictors of impact, but the generality of this approach clearly requires further derivation of FRs across taxa.

Gammarus pulex had near identical FRs as natives in France and invaders in Ireland. Morphological, behavioural, physiological and genetic differences are common in species in native as compared to introduced ranges (e.g. Tsutsui et al. 2000), but FRs appear to be consistent in these amphipods. Thus, derivation of FRs in native ranges may give good indications of predatory impacts in invasive ranges.

Invasion biology is under pressure to move from understanding to prediction, but this remains elusive. Ideally, any such methodologies should be relatively straightforward and have some predictive power, with wide taxonomic and ecological applicability. In our amphipod example, we have shown some potential of comparative FRs to achieve this, although other factors such as invader abundance could be important (see above). Such measures are strictly empirical, not theoretical models, and thus do not explain the reasons behind differences (see Jeschke et al. 2002) nor discriminate among theoretical models (see Fussmann \& Blasius 2005). The present approach does provide empirical evidence for potential community impact using standard protocols. This may be developed to provide more precise predictions of impact and more efficient targeting of resources in tackling damaging invasive species.

We thank the European Science Foundation for funding (LINKECOL). Martin Thiel and several anonymous reviewers greatly improved the manuscript.

Beckerman, A. P. 2005 The shape of things eaten: the functional response of herbivores foraging adaptively. Oikos 110, 591-601. (doi:10.1111/j.0030-1299.2005.13546.x)

Devin, S. \& Beisel, J.-N. 2007 Biological and ecological characteristics of invasive species: a gammarid study. Biol. Invasions 9, 13-24. (doi:10.1007/s10530-006-9001-0)
Dick, J. T. A., Platvoet, D. \& Kelly, D. W. 2002 Predatory impact of the freshwater invader, Dikerogammarus villosus (Crustacea: Amphipoda). Can. F. Fish. Aquat. Sci. 59, 1078-1084. (doi:10.1139/f02-074)

Fussmann, G. F. \& Blasius, B. 2005 Community response to enrichment is highly sensitive to model structure. Biol. Lett. 1, 9-12. (doi:10.1098/rsbl.2004.0246)

Holling, C. S. 1959 Some characteristics of simple types of predation and parasitism. Can. Entomol. 91, 385-398.

Hooff, R. C. \& Bollens, S. M. 2004 Functional response and potential predatory impact of Tortanus dextrilobatus, a carnivorous copepod recently introduced to the San Francisco Estuary. Mar. Ecol. Prog. Ser. 277, 167-179. (doi:10.3354/meps277167)

Jeschke, J. M., Kopp, M. \& Tollrian, R. 2002 Predator functional responses: discriminating between handling and digesting prey. Ecol. Monogr. 72, 95-112.

Jones, D. B., Giles, K. L., Berberet, R. C., Royer, T. A., Elliot, N. C. \& Payton, M. E. 2003 Functional responses of an introduced parasitoid and an indigenous parasitoid on greenbug at four temperatures. Environ. Entomol. 32, 425-432.

Kelly, D. W. \& Dick, J. T. A. 2005 Introduction of the non-indigenous amphipod Gammarus pulex alters population dynamics and diet of juvenile trout Salmo trutta. Freshw. Biol. 50, 127-140. (doi:10.1111/j.1365-2427. 2004.01315.x)

Kelly, D. W., Bailey, R. J. E., MacNeil, C., Dick, J. T. A. \& McDonald, R. A. 2006 Invasion by the amphipod Gammarus pulex alters community composition of native freshwater macroinvertebrates. Divers. Distrib. 12, 525-534. (doi:10.1111/j.1366-9516.2006.00275.x)

Leppäkoski, E., Gollasch, S. \& Olenin, S. 2002 Invasive aquatic species of Europe: distribution, impacts and management. Dordrecht, The Netherlands: Kluwer Academic Publishers.

Lockwood, J. L., Cassey, P. \& Blackburn, T. 2005 The role of propagule pressure in explaining species invasions. Trends Ecol. Evol. 20, 223-228. (doi:10.1016/j.tree.2005. 02.004)

Nehring, S. 2006 The Ponto-Caspian amphipod Obesogammarus obesus (Sars, 1894) arrived the Rhine River via the Main-Danube Canal. Aquat. Invasions 1, 148-153.

Pöckl, M. 2007 Strategies of a successful new invader in European fresh waters: fecundity and reproductive potential of the Ponto-Caspian amphipod Dikerogammarus villosus in the Austrian Danube, compared with 
the indigenous Gammarus fossarum and $G$. roeseli. Freshw. Biol. 52, 50-63. (doi:10.1111/j.1365-2427.2006. 01671.x)

Radford, I. J., Dickinson, K. J. M. \& Lord, J. M. 2007 Functional and performance comparisons of invasive Hieracium lepidulum and co-occurring species in New Zealand. Aust. Ecol. 32, 338-354. (doi:10.1111/j.14429993.2007.01700.x)

Ricciardi, A. 2003 Predicting the impacts of an introduced species from its invasion history: an empirical approach applied to zebra mussel invasions. Freshw. Biol. 48, 972-981. (doi:10.1046/j.1365-2427.2003.01071.x)

Ricciardi, A. 2006 Patterns of invasion in the Laurentian Great Lakes in relation to changes in vector activity. Divers. Distrib. 12, 425-433. (doi:10.1111/j.1366-9516. 2006.00262.x)

Ricciardi, A. \& Cohen, J. 2007 The invasiveness of an introduced species does not predict its impact. Biol. Invasions 9, 309-315. (doi:10.1007/s10530-006-9034-4)

Ricciardi, A. \& Rasmussen, J. B. 1998 Predicting the identity and impact of future biological invaders: a priority for aquatic resource management. Can. F. Fish. Aquat. Sci. 55, 1759-1765. (doi:10.1139/cjfas-55-7-1759)
Tittizer, T. 1996 Main-Danube canal now a short cut for fauna. Danube Watch 2, 7-8.

Tsutsui, N. D., Suarez, A. V., Holway, D. A. \& Case, T. J. 2000 Reduced genetic variation and the success of an invasive species. Proc. Natl Acad. Sci. USA 97, 5948-5953. (doi:10.1073/pnas.100110397)

van Riel, M. C., van der Velde, G., Rajagopal, S., Marguillier, S., Dehairs, F. \& de Vaate, A. B. 2006 Trophic relationships in the Rhine food web during invasion and after establishment of the Ponto-Caspian invader Dikerogammarus villosus. Hydrobiologia 565, 39-58. (doi:10.1007/s10750-005-1904-8)

von Holle, B. \& Simberloff, D. 2005 Ecological resistance to biological invasion overwhelmed by propagule pressure. Ecology 86, 3212-3218. (doi:10.1890/05-0427)

Wanless, R. M., Angel, A., Cuthbert, R. J., Hilton, G. M. \& Ryan, P. G. 2007 Can predation by invasive mice drive seabird extinctions? Biol. Lett. 3, 241-244. (doi:10. 1098/rsbl.2007.0120)

Zaret, T. M. \& Paine, R. T. 1973 Species introduction in a tropical lake. Science 182, 449-455. (doi:10.1126/ science.182.4111.449) 